\title{
INFLUENZA VACCINATION AMONG HEALTHCARE WORKERS IN A UNIVERSITY CHILDREN'S HOSPITAL
}

\author{
Terhi Tapiainen, MD; Gurli Bär, MD; Urs B. Schaad, MD; Ulrich Heininger, MD
}

\begin{abstract}
OBJECTIVES: To evaluate the attitudes of pediatric healthcare workers (HCWs) toward influenza vaccination and to increase their rate of immunization.

METHODS: A survey was conducted among pediatric HCWs using an anonymous questionnaire. Survey results were used to design an intervention to increase the immunization rate of staff. Immunization rates before (2003-2004) and after (2004-2005) intervention were assessed using immunization clinic records.

SETTING: A university children's hospital in Switzerland.

INTERVENTIONS: (1) An informational letter based on misconceptions noted in the survey, (2) educational conversations with head nurses, (3) more "walk-in" immunization clinics, and (4) a direct offer of influenza immunization on the wards.

RESULTS: Among vaccine nonrecipients, doubts about

the efficacy and necessity of influenza immunization were prevalent and more often reported by nurses than physicians ( $75 \%$ vs $41 \%, P=.002$; and $55 \%$ vs $23 \%, P=.001$, respectively). Physicians more often than nurses reported lack of time as a reason for not receiving influenza vaccination ( $23 \%$ vs $5 \%, P=.01)$. After intervention, the immunization rate of HCWs increased from $19 \%$ to $24 \%(P=.03)$. The immunization rate of physicians increased from $43 \%$ to $64 \%(P=.004)$. No change was noted among nurses ( $13 \%$ vs $14 \%$ ) and other HCWs ( $16 \%$ vs $16 \%)$.

CONCLUSIONS: Misconceptions about influenza vaccination were prevalent among pediatric staff, particularly nurses. Active promotion and educational efforts were successful in increasing the immunization rate of physicians but not nurses and other HCWs (Infect Control Hosp Epidemiol 2005;26:855-858).
\end{abstract}

Healthy infants and young children without underlying conditions are at increased risk for hospitalization for influenza at rates comparable to those observed in adults in high-risk groups. ${ }^{1,2}$ Critical life-threatening influenza is more frequent among infants and children with chronic underlying disease, and almost one-third of influenza cases admitted to pediatric intensive care units are nosocomial. ${ }^{3}$ Moreover, nosocomial influenza outbreaks have been described in many hospital settings, including neonatal intensive care units, organ transplant units, and infectious disease wards. ${ }^{4-7}$

Influenza vaccination for healthcare workers ( $\mathrm{HCWs)}$ is recommended and reimbursed in many countries to reduce transmission of influenza to high-risk patients. ${ }^{8,9} \mathrm{Nev}$ ertheless, the immunization rate of HCWs often remains low. ${ }^{10-12}$ In pediatric hospitals, the acceptance of influenza immunization among HCWs is particularly important as many chronic patients are younger than 6 months and therefore cannot be immunized directly. ${ }^{8}$

Our institution has offered information and influenza immunization free of charge to all HCWs for several years. Despite these efforts, the overall immunization rate of our staff has remained low. A previous study performed by members of our group revealed that many unimmunized pediatricians in our hospital had doubts about the necessity and efficacy of influenza vaccination. ${ }^{13} \mathrm{We}$ hypothesized that there may be important differences in reasons for accepting or declining immunization in different occupational groups that should be considered when influenza immunization is promoted for all HCWs. Therefore, we conducted a survey to evaluate reasons for immunization or refusal of immunization. The results were used to design an intervention to increase the rate of immunization among our staff.

\section{METHODS}

After the 2003-2004 influenza season, an anonymous questionnaire was sent to all HCWs in our institution. The questionnaire and study protocol were approved by the Ethical Committee of the University of Basel Medical Faculty. Response rates among vaccine recipients and nonrecipients were calculated by comparing the figures obtained from returned questionnaires with data regarding immunizations administered in our immunization clinic. Information about

The authors are from the University Children's Hospital, Basel, Switzerland.

Address reprint requests to Ulrich Heininger, MD, University Children's Hospital, PO Box, CH-4005 Basel, Switzerland.ulrich.heininger@unibas.ch

Supported in part by a grant from the European Society of Paediatric Infectious Diseases to Dr. Tapiainen, who is currently a research fellow.

The authors thank the staff of the University Children's Hospital who participated in this study. They also thank Dr. Franziska Zenger, Mrs. Hildegard Schär, and Mrs. Esther Schilling for their technical support. 
TABLE 1

DESIGN OF THE INTERVENTION TO INCREASE INFLUENZA IMMUNIZATION RATES BASED ON THE RESULTS OF THE ATTITUDE SURVEY DURING THE PREVIOUS INFLUENZA SEASON

\begin{tabular}{|c|c|}
\hline Perlod & Intervention \\
\hline \multirow[t]{9}{*}{ Before walk-in immunization clinics were open } & $\begin{array}{l}\text { Informational letter to all healthcare workers based on the results of the previous year's } \\
\text { attitude survey }\end{array}$ \\
\hline & What is influenza? \\
\hline & Efficacy of influenza immunization \\
\hline & Side effects \\
\hline & Patient protection \\
\hline & Real contraindications \\
\hline & Educational conversations with the head nurses of each ward \\
\hline & General information \\
\hline & Patient protection \\
\hline \multirow[t]{2}{*}{ Free walk-in immunization clinics } & Increased number \\
\hline & Extended to wards not located in the main hospital \\
\hline After walk-in immunization clinics were closed & Opportunity for voluntary immunization was directly offered on wards \\
\hline
\end{tabular}

immunizations performed outside the hospital (ie, by family physicians) was not solicited.

The questionnaire comprised several multiple-choice questions. Reasons for immunization were evaluated using the following alternatives: (1) to reduce my own risk, (2) to reduce the transmission of influenza from me to patients, and (3) to set a good example for my patients because I recommend influenza vaccination. As reasons for refusal of immunization, the following alternatives were offered: (1) I am generally not convinced about influenza vaccination, (2) I am afraid of possible side effects of influenza vaccination, (3) I am not convinced about the efficacy of influenza vaccination, (4) I am afraid of injections, (5) I did not have time for immunization, and (6) I thought that the offer to get influenza vaccination was obtrusive. All negative arguments were based on comments by HCWs during informal conversations before the first survey.

An intervention to increase the immunization rates was designed based on the results of the attitude survey (Table 1). Data on immunization rates were obtained using immunization clinic records. Immunization rates before (2003-2004) and after (2004-2005) intervention were compared. Attitudes were reevaluated after intervention using the same anonymous questionnaire with the addition of one question about side effects after immunization.

The differences in immunization rates before and after intervention and between occupational groups were analyzed by chi-square tests. Ninety-five percent confidence intervals for immunizations rates were calculated. Statistical analysis was performed with the statistical program SPSS (version 11.0; SPSS, Inc., Chicago, IL).

\section{RESULTS}

In total, $406(75 \%)$ of $538 \mathrm{HCWs}$ returned the questionnaire after the 2003-2004 influenza season. The re- sponse rate was $70 \%$ (63 of 90 ) among physicians, $78 \%$ (249 of 320) among nurses, and 70\% (90 of 128) among other HCWs. Information on the occupational group was missing from four returned questionnaires. The response rate was lower among unimmunized physicians (45\%), unimmunized nurses $(72 \%)$, and unimmunized other HCWs $(62 \%)$ than among those who had been immunized $(100 \%$ for all three groups).

The attitudes of 60 of 63 physicians, 232 of 249 nurses, and 60 of 90 other HCWs who reported having regular patient contact were further analyzed (Table 2). The number of immunized nurses based on self-assessment $(n=45)$ was higher than the number of immunizations performed among nurses in our clinic during the 2003-2004 season $(n=40$; Table 3), indicating that some nurses had been immunized elsewhere. Doubts about the efficacy and necessity of influenza vaccination were the most common reasons for refusal of immunization, followed by fear of side effects and missed opportunities. Physicians reported doubts about efficacy and necessity less often than did nurses and other HCWs. Furthermore, physicians reported that they remained unimmunized due to lack of time or missed opportunities more often than did other HCWs.

After intervention, the immunization rate increased from $43 \%$ (39 of 90 ) to $64 \%$ ( 66 of 103 ) among physicians, but remained unchanged among nurses and other HCWs (Table 3).

The response rate of the second attitude survey (ie, $71 \%$; 394 of 554 ) was similar to that of the first survey. Specifically, rates were $71 \%$ (73 of 103) among physicians, $71 \%$ (229 of 323 ) among nurses, and $68 \%$ (87 of 128) among other $\mathrm{HCWs}$. Information on the occupational group was missing from five questionnaires. The reasons for immunization of $\mathrm{HCWs}$ with regular patient contact remained similar in all 
TABLE 2

REASONS FOR IMMUNIZATION OR NONIMMUNIZATION AGAINST INFLUENZA BEFORE INTERVENTION (2003-2004) AMONG PHYSICIANS, NURSES, AND OTHER HEALTHCARE WORKERS WITH REGULAR PATIENT CONTACT*

\begin{tabular}{|c|c|c|c|c|}
\hline Reason for Immunization & Physiclans ( $\mathbf{N}=\mathbf{3 8})$ & Nurses (N = 45) & Other HCWs (N = 13) & $\mathbf{P}$ \\
\hline Self-protection & $36(95 \%)$ & $39(87 \%)$ & $12(92 \%)$ & .44 \\
\hline To reduce transmission to patients & $32(84 \%)$ & $27(60 \%)$ & $10(77 \%)$ & $.046^{\dagger}$ \\
\hline To set a good example for patients & $14(37 \%)$ & $5(11 \%)$ & $3(23 \%)$ & $.021^{\dagger}$ \\
\hline No reason & 0 & $2(4 \%)$ & 0 & ND \\
\hline Reason for Nonlmmunization & Physicians ( $N=22$ ) & Nurses ( $N=187$ ) & Other HCWs (N = 35) & $\boldsymbol{P}$ \\
\hline Not convinced about efficacy & $9(41 \%)$ & $141(75 \%)$ & $22(63 \%)$ & $.002^{+}$ \\
\hline Not convinced about necessity & $5(23 \%)$ & $103(55 \%)$ & $26(74 \%)$ & $.001^{+}$ \\
\hline Fear of side effects & $6(27 \%)$ & $53(28 \%)$ & $9(26 \%)$ & .972 \\
\hline Missed opportunities & $5(23 \%)$ & $10(5 \%)$ & $2(6 \%)$ & $.010^{\dagger}$ \\
\hline Fear of injection & 0 & $9(5 \%)$ & $3(9 \%)$ & ND \\
\hline Dislike of initiative & $3(14 \%)$ & $21(11 \%)$ & $5(14 \%)$ & .846 \\
\hline Contraindication & 0 & $1(0.5 \%)$ & 0 & ND \\
\hline No reason & $1(5 \%)$ & $3(1.5 \%)$ & 0 & $\mathrm{ND}$ \\
\hline
\end{tabular}

$\mathrm{HCW}$ = healthcare worker; NI) - not determined.

* One or more reasons could be given.

${ }^{+} P<.05$.

TABLE 3

INFLUENZA IMMUNIZATION RATES BEFORE (2003-2004) AND AFTER (2004-2005) INTERVENTION AMONG HEALTHCARE WORKERS WITH OR WITHOUT REGULAR PATIENT CONTACT BASED ON DATA FROM THE HOSPITAL IMMUNIZATION CLINIC,

\begin{tabular}{|c|c|c|c|c|c|c|c|}
\hline \multirow[b]{2}{*}{ Occupation } & \multicolumn{3}{|c|}{ 2003-2004 } & \multicolumn{3}{|c|}{ 2004-2005 } & \multirow[b]{2}{*}{$\mathbf{P}$} \\
\hline & No. Immunlzed/Total & $\%$ & $\mathrm{Cl}_{95}$ & No. Immunlzed/Total & $\%$ & $\mathrm{Cl}_{95}$ & \\
\hline Physician* & $39 / 90$ & 43 & $33 \%$ to $54 \%$ & $66 / 103$ & 64 & $55 \%$ to $75 \%$ & $.004^{\dagger}$ \\
\hline Nurse & $40 / 320$ & 13 & $9 \%$ to $16 \%$ & $46 / 323$ & 14 & $10 \%$ to $18 \%$ & .52 \\
\hline Other HCW & $21 / 128$ & 16 & $10 \%$ to $23 \%$ & $21 / 128$ & 16 & $10 \%$ to $23 \%$ & 1.0 \\
\hline Total & $100 / 538$ & 19 & $15 \%$ to $22 \%$ & $133 / 554$ & 24 & $20 \%$ to $28 \%$ & $.03^{\dagger}$ \\
\hline
\end{tabular}

$\mathrm{Cl}_{45}=95 \%$ confidence interval; $\mathrm{HCW}=$ healthcare worker.

*The number of physicians was greater during the 2004-2005 influenza season due to an increased number of interns and residents. ${ }^{+} P<.05$.

occupational groups (data not shown), with the exception that patient protection (83\%) instead of self-protection (74\%) became the most prevalent reason for immunization reported by physicians. Reasons for refusal of immunization also remained unchanged in all occupational groups, with the exception that efficacy doubts among nurses decreased from $75 \%$ to $58 \%(P=.001)$ after intervention.

Side effects after immunization were reported by 25 (20\%) of 127 vaccine recipients who returned the second questionnaire: systemic reactions such as fever were reported by $18(14 \%)$ of the HCWs on days 0 to 4 after immunization and any local reaction by $7(6 \%)$ of the HCWs on days 0 to 2 after immunization. No serious adverse events were reported.

\section{DISCUSSION}

Many surveys have been published that report the attitudes of HCWs toward influenza immunization and a positive relationship between knowledge and compliance. ${ }^{14-20}$ However, only a few studies have tested the effectiveness of different intervention methods to increase the rate of immunization among $\mathrm{HCW}$ in practice. ${ }^{21-23}$

In a randomized study among residents and junior medical students, an educational personal letter and a direct offer of influenza immunization in clinics and conferences increased the compliance most effectively. ${ }^{21}$ In a study among HCWs caring for high-risk pediatric patients, posters and educational fact cards distributed to clinics were associated with an increased immunization rate. ${ }^{22}$ Finally, an influenza immunization campaign on high-risk wards of a university hospital showed that educational efforts based on the results of an attitude survey and the on-site availability of a vaccination nurse were the most important factors increasing the rate of immunization among $\mathrm{HCWs}{ }^{23}$ 
Our intervention was based on the results of the preceding attitude survey showing that doubts about the necessity and efficacy of immunization were prevalent among our staff, particularly nurses. Moreover, lack of time was an important reason for physicians' not receiving influenza vaccine. Personal educational letters and increased opportunities for immunization were practical and effective ways to improve compliance with influenza immunization among physicians in our hospital. Disappointingly, we failed to increase the rate of immunization among nurses, although we recognized the greater need for education among nurses based on the results of our survey. A similar reluctance toward influenza immunization among nurses has been reported in previous studies. ${ }^{15,19,23}$

Not surprisingly, some vaccinated HCWs reported adverse events that they considered to be side effects of immunization, but the rate was comparatively low. When active prospective surveillance of side effects was applied in a randomized study with 849 healthy working adults, the rate of systemic side effects after influenza vaccination did not differ between recipients of placebo (35\%) and vaccine $(34 \%) .{ }^{24}$ In the same study, mild arm soreness was noted by $24 \%$ of placebo recipients and by $64 \%$ of influenza vaccine recipients.

Misconceptions about influenza vaccination were prevalent among pediatric staff, particularly nurses. Active promotion and educational efforts based on the results of an attitude survey were successful in increasing the rate of immunization of physicians but not nurses and other HCWs.

\section{REFERENCES}

1. Neuzil KM, Mellen BG, Wright PF, Mitchel EF Jr, Griffin MR. The effect of influenza on hospitalizations, outpatient visits, and courses of antibiotics in children. $N$ Engl J Med 2000;342:225-231.

2. Izurieta HS, Thompson WW, Kramarz P, et al. Influenza and the rates of hospitalization for respiratory disease among infants and young children. N Engl J Med 2000;342:232-239.

3. Kappagoda C, Isaacs D, Mellis C, Peat J, De Silva L, O'Connell A. Critical influenza virus infection. J Paediatr Child Health 2000;36:318321

4. Meibalane R, Sedmak GV, Sasidharan P, Garg P, Grausz JP. Outbreak of influenza in a neonatal intensive care unit. $J$ Pediatr 1977;91:974976 .
5. Munoz FM, Campbell JR, Atmar RL, et al. Influenza A virus outbreak in a neonatal intensive care unit. Pediatr Infect Dis J 1999:18:811-815.

6. Malavaud S, Malavaud B, Sandres K, et al. Nosocomial outbreak of influenza virus A (H3N2) infection in a solid organ transplant department. Transplantation 2001;72:535-537.

7. Horcajada JP, Pumarola T, Martinez JA, et al. A nosocomial outbreak of influenza during a period without influenza epidemic activity. Eur Respir J 2003;21:303-307.

8. Bridges CB, Harper SA, Fukuda K, Uyeki TM, Cox NJ, Singleton JA Prevention and control of influenza: recommendations of the Advisory Committee on Immunization Practices (ACIP). MMWR Recomm Rep 2003;52(RR-8):1-34.

9. Ambrosch F, Fedson DS. Influenza vaccination in 29 countries: an update to 1997. Pharmacoeconomics 1999;16(suppl 1):47-54.

10. Eisenfeld L, Perl L, Burke G, et al. Lack of compliance with influenza immunization for caretakers of neonatal intensive care unit patients. Am I Infect Control 1994;22:307-311.

11. Rehmet S, Ammon A, Pfaff G, Bocter N, Petersen LR. Cross-sectional study on influenza vaccination, Germany, 1999-2000. Emerg Infect Dis 2002;8:1442-1447.

12. Smedley J, Palmer C, Baird J, Barker M. A survey of the delivery and uptake of influenza vaccine among health care workers. Occup Med (Lond) 2002;52:271-276.

13. Heininger U, Bachler M, Schaad UB. Attitudes of pediatricians regarding influenza self-immunization: a survey in a Swiss university children's hospital. Pediatr Infect Dis J 2003;22:391-394.

14. Nafziger DA, Herwaldt LA. Attitudes of internal medicine residents regarding influenza vaccination. Infect Control Hosp Epidemiol 1994;15:3235 .

15. Weingarten $S$, Riedinger $M$, Bolton LB, Miles P, Ault M. Barriers to influenza vaccine acceptance: a survey of physicians and nurses. $\mathrm{Am}$ I Infect Control 1989;17:202-207.

16. Watanakunakorn C, Ellis G, Gemmel D. Attitude of healthcare personnel regarding influenza immunization. Infect Control Hosp Epidemiol 1993;14:17-20.

17. Yassi A, Murdzak C, Cheang M, Tran N, Aoki FY. Influenza immunization: knowledge, attitude and behaviour of health care workers. Can I Infect Control 1994;9:103-108.

18. Nichol KL, Hauge M. Influenza vaccination of healthcare workers. Infect Control Hosp Epidemiol 1997;18:189-194.

19. Martinello RA, Jones L, Topal JE. Correlation between healthcare workers' knowledge of influenza vaccine and vaccine receipt. Infect Control Hosp Epidemiol 2003;24:845-847.

20. Lester RT, McGeer A, Tomlinson G, Detky AS. Use of, effectiveness of, and attitudes regarding influenza vaccine among house staff. In fect Control Hosp Epidemiol 2003;24:839-844.

21. Ohrt CK, McKinney WP. Achieving compliance with influenza immunization of medical house staff and students: a randomized controlled trial. JAMA 1992;267:1377-1380.

22. Bryant KA, Stover B, Cain L, Levine GL, Siegel J, Jarvis WR. Improving influenza immunization rates among healthcare workers caring for high-risk pediatric patients. Infect Control Hosp Epidemiol 2004;25:912-917.

23. Harbarth S, Siegrist CA, Schira JC, Wunderli W, Pittet D. Influenza immunization: improving compliance of healthcare workers. Infect Control Hosp Epidemiol 1998;19:337-342.

24. Nichol KL, Margolis KL, Lind A, et al. Side effects associated with influenza vaccination in healthy working adults: a randomized, placebo-controlled trial. Arch Intern Med 1996;156:1546-1550. 